\title{
From the History of Russian Computer Science
}

\author{
Yakov Fet \\ Institute of Computational Mathematics and Mathematical Geophysics of the Siberian \\ Branch of the Russian Academy of Sciences, Novosibirsk, Russia \\ fetassd.sscc.ru
}

\begin{abstract}
This article includes a few passages from the History of Computer Science relating to the events of the middle of the last century. The first part of this article contains a short biography of Norbert Wiener, who is considered to be one of the fathers of modern computer science. This part pays particular attention to Norbert Wiener's visit to Moscow in the summer of 1960. The other parts of the article focus on life and work of Aleksey Lyapunov, Leonid Kantorovich and Andrey Ershov. The outstanding professional achievements of these Russian scientists, as well as their moral perfection, can set an example for modern students and young professionals.
\end{abstract}

Keywords: Computer Science, Norbert Wiener, Aleksey Lyapunov, Leonid Kantorovich, Andrey Ershov, human quality.

\section{Introduction}

The works of modern humanists are characterized by a view of human qualities, which we consider to be very important. Individual qualities and characteristics of one person can hardly be measured or compared with the analogous qualities and characteristics of the other. Nevertheless, all of us use an intuitive (and, of course, individual!) scale to evaluate behavior, actions and statements of other people.

When speaking about prominent scientists, we often use the phrase 'A Man with a capital letter'. And we think that, in this high estimation, the civic characteristics that find expression in behavior, actions, attitude to other people and response to their actions and statements etc. are probably even more appreciated than just scientific achievements. A Man with a capital letter is a high class professional and one of great moral excellence at the same time. In 1968, Aurelio Peccei, a recognized expert in the field of management, founded and headed one of the most powerful democratic movements of the XX century - The Club of Rome. The scientists who formed the Club believed that our society could be improved by the way of the growth and development of human qualities which are the main reserve and a powerful driving force behind progress.

In 1977, Aurelio Peccei wrote in his book 'The Human Quality' [1]:

"Until our so called technological society becomes as well a human society, violence will proceed its triumphal demonstration and we will continue to fight special cases of this general phenomenon without understanding the origins of the violence." 
We are lucky to find in our life those special, wonderful, charismatic people that emerge from time to time in the history of science as well as in the history of Computer Science. Except for their brilliant intellectual capabilities, they possess the treasure of personal characteristics that are invaluable to history and society. Moral perfection of such scientists can be a great example for modern students and teachers.

This article is dedicated to the outstanding scientists - humanists who lived among us, who worked and attained most important achievements of their lives before our very eyes. They really are a living example to learn from! And we believe that their contributions to the development of human qualities in our society are their greatest achievements.

\section{Norbert Wiener}

This article deals with the history of the Russian Computer Science, but still I decided to locate the part called 'Norbert Wiener' at the very beginning of it, because Wiener's 'Cybernetics' really is, as a matter of fact, the beginning of the history of Computer Science - especially taking into account that 'Cybernetics' was published in 1948, when the first successful computers were built.

***

There are some exceptional circumstances in the biography of Norbert Wiener that must have had a great impact on his personality at the very beginning of his life, affecting both his human qualities and his later scientific work. Norbert Wiener was born to a Jewish family on November 26, 1894, in the USA. His father, Leo Wiener (1862-1939), immigrated to America from Bialystock (Russia) in 1880.

The uncommon personality of Leo Wiener and his special role in the process of raising his children had an important place in the life and work of Norbert Wiener. When young, Leo Wiener was a strong follower of the philosophy of Leo Tolstoy. In 1880, when he was 18, Leo Wiener decided to go to Central America with his friend who was a Tolstoyan, too. They intended to found there a humanistic community. They swore they would never drink alcohol, smoke and eat meat. The friend was lost somewhere along the way, and Leo went through many adventures and at last arrived in Kansas City, Missouri, without a penny in his pocket. Having faced many obstacles to overcome, he managed to get the job of a teacher in foreign languages (later, he was a Professor of Slavic Languages at the famous Harvard University in Cambridge, Massachusetts). Leo got married in 1893. One year later, his son Norbert was born in the city of Columbia, Missouri.

Those who read the biographies of Norbert Wiener and his father often ask themselves a question that has been discussed a lot by both historians and geneticists: is it possible to inherit intellectual qualities? Really, it happens sometimes in the history of science and culture that several famous people come from the same family. However, I don't believe in the fantastic ideas of eugenics. Development and manifestation of mental abilities depends mostly on the influence of social environment, traditions, upbringing and education.

Norbert Wiener's talent manifested itself very early. He had a good reason to choose the title 'Ex-Prodigy: My Childhood and Youth' [2] for the book about his childhood. Leo Wiener never concealed his intention to bring up child prodigies. 
Norbert's father took complete control over his education. He was a very energetic and exigent man and maybe sometimes he went too far - but the facts speak for themselves.

We know many other examples of attaining high intellectual achievements in result of combination of natural abilities, favorable environment, upbringing and education. A striking example is the family of Aleksey Lyapunov and the story of his life and work. Aleksey Lyapunov was a brilliant scientist, teacher and humanist, he played a decisive role in formation and development of Computer Science in Russia. It is appropriate to explain here the importance of establishing specialized schools and the system of admission of the pupils on a competitive basis. In the 60s, a good example of the rational and effective method to organize school education was the PhysicoMathematical School (PMS) founded in Novosibirsk Akademgorodok (the Novosibirsk Academic Village) by Aleksey Lyapunov and other Siberian scientists.

So, Wiener's father took the boy away from the school and educated him at home for several years; the main subjects were mathematics and foreign languages. In 1903, the Wiener family moved to Harvard, Massachusetts. Norbert was admitted to high school and studied there for three years. After graduating from this school in 1906 (at 11 years of age) Norbert Wiener entered Tuft's College. At the same time, he was continuing home education.

He was awarded a bachelor in mathematics in 1909 (at the age of 14), whereupon he began graduate studies at Harvard. He studied mathematical logic and philosophy of mathematics, and was awarded a PhD degree in 1913. By the time he was under 19 years old, which was about 6 years less than the average age of a person who attained a doctorate.

$$
* * *
$$

His working life began in 1915. During 1915-16 he was a teaching assistant at the Philosophy department of Harvard University. After that, he tried many jobs. He worked for several months as a journalist for The Boston Herald and even wanted to join the military.

At last, with the assistance of mathematician W.F. Osgood who was a friend of Leo Wiener, Norbert became an instructor of mathematics at the Massachusetts Institute of Technology, where he worked for the rest of his live. His talent blossomed out at MIT. Maybe he finally found his real calling in mathematics; maybe his permanent work gave him a feeling of safety and self-esteem; maybe at the age of 24 the former prodigy attained stable equilibrium and was ready to become a genius. In any case, during the first ten years of working at MIT Norbert Wiener made his most striking contributions to abstract mathematics.

$$
* * *
$$

Wiener invented the word 'cybernetics' which comes from the Greek $\chi \nu \beta \varepsilon \rho v \eta \dot{\tau}\rceil$, meaning 'steersman'. In the Webster Dictionary the word 'cybernetics' is defined as: the study of human control functions and of mechanical and electronic systems designed to replace them, involving the application of statistical mechanics to communication engineering.

In his book 'I am a Mathematician' [3] Wiener says that cybernetics is the most appropriate word he could find "to define the art and the science of control in the wide range of applications of this notion". 
Like many other great things, this book appeared as the result of a concurrence of casual circumstances. In the summer of 1947, Wiener traveled to France to attend a mathematics conference that was taking place in Nancy. There he met M. Freyman, who was a mathematician and worked for the publishing house 'Hermann \& Co.'. Wiener received from Freyman a proposition to write a book dealing with the main ideas of his works in the field of control and communication.

Wiener willingly signed the contract and continued his journey. The book was written in Mexico, in the late autumn of the same year, and dedicated to Arturo Rosenblueth. And the first lines of 'Cybernetics' told:

"This book represents the outcome, after more than a decade, of a program of work undertaken jointly with Dr. Arturo Rosenblueth, then of the Harvard Medical School and now of the Instituto Nacional de Cardiologia of Mexico" [4].

The friendship and co-operation with Rosenblueth opened to Wiener, who was mainly a mathematician, the world of biology and medicine. The idea of a universal methodological approach to all fields of science emerged and rooted in his mind. Remarkable generalizations made by Wiener in 1948, rested upon a solid foundation.

Wiener's book appeared in 1948. It was published simultaneously in France and in the USA under the title 'Cybernetics or Control and Communication in the Animal and the Machine'. This book instantly turned Wiener into a kind of scientific superstar.

Since then, the name of Wiener and the word 'cybernetics' became inseparable from the new science and its numerous applications that by now are covered by the terms informatics and information technologies.

Talking about cybernetics, we have to pay special attention to the importance of communication or information transmission for the functioning of any natural organisms and technical devices. Now we say that informatics, which stems from cybernetics, is a group of scientific fields dealing with general characteristics of information and the ways and means of creating, storing and transferring information. It is hard to overestimate the significance of informatics to the modern society.

At present, informatics in all its applications depends upon computers. The first modern computers and Wiener's 'Cybernetics' appeared approximately at the same time.

In the Summer of 1960 (from June 27 to July 02) the First International Congress of the International Federation of Automatic Control (IFAC) took place in Moscow. More than 1,200 scientists from 30 countries arrived in Moscow. Actually, it was the first congress on such a large scale conducted in the Soviet Union. On one hand, this event could only be possible in the time of Khrushchev's 'thaw' - and it was the first attempt to put an end to the isolation of Soviet science. On the other, it clearly showed a general interest in the achievements of Soviet science, and in particular, in the field of automatic control and cybernetics.

1,200 delegates - that was impressive! One of the active participants of the Congress 1960, Eric Nappelbaum (who was just an interpreter during the public speeches held by Wiener in Moscow), remembered that: 
...many of the people who had come to the Congress were not intending to participate in the scientific event. They were very eager to know more about our country and took the unique opportunity to come and see everything with their own eyes. That was the reason why there were so many people not directly connected to the subject of Automatic Control [5].

No wonder, that Norbert Wiener was greeted in Moscow with great enthusiasm. He participated in the Opening Ceremony of the Congress which took place at the State University of Moscow on the $27^{\text {th }}$ of June. On June 28, he gave a lecture on 'Brain Waves and Self-Organizing Systems' in the Big Lecture Hall of the Polytechnic Museum. As it often happens when a public speech held by popular scientist or poet take place, the Big Hall couldn't hold all the people who attended, so some had to sit on the stairs or in the gangways. The lecture had to be repeated on the $1^{\text {st }}$ of July.

Of course, the interest was mutual. The main Soviet newspapers and magazines did their best to organize and publish discussions with Norbert Wiener - it is not every day you get the chance to meet such a great person in Moscow!

The magazine 'Voprosy Filosofii' ('Problems of Philosophy') invited Norbert Wiener to visit its editorial office. A meeting between Wiener and Soviet philosophers was organized there on July 5, 1960. A shorthand record of this discussion was published in the Issue 9 of this magazine.

The magazine 'Priroda' ('Nature') published in its Issue 8, 1960 an interview entitled: 'Cybernetics and Humans. A Conversation with Professor N. Wiener'. (The same interview was later included in the second Russian edition of Wiener's 'Cybernetics' as one of the Appendices) [6].

On June 30, 1960, the newspaper 'Literaturnaya Gazeta' ('Literary Newspaper') published materials of an interview with Wiener under the title 'Cybernetics and the Literature' [7]:

\section{Wiener:}

I would like to tell you about my first Moscow impressions. I like the city and I am very impressed with the young Soviet scientists I met here. They are polite, proper and very nice people and excellent professionals. I would be pleased to have such colleagues.

The work that I have been doing over the last 30 years has much in common with the work of the Soviet scientists. When I'm reading the papers of Academician Kolmogorov, I feel like I am sometimes reading my own thoughts - it's just what I wanted to say. And I know that he feels the same reading my papers. Both of us profit enormously from such collaboration.

\section{LG:}

Could you tell us what are you working on right now?

\section{Wiener:}

Right now I'm working on a second edition of 'Cybernetics'...

At the same time, I'm writing a new novel. In my free time, I'm a writer. It's not just a way of relaxation. It's always interesting to me how the circumstances of the life affect a person's character and what destiny awaits him or her. My first novel 'The Tempter' [8] was published in November 1959. It deals with a conflict between a scientist's ideals and 
his wish to make a good career, which is very typical for America. The epigraph of the novel says: "To those scientists who prefer to look for the truth and not for earthly blessings". At the center of the narrative is the destiny of the engineer Gregory James who was born in Russia, in the city of Odessa, and immigrated to America before the First World War. My choice of the main hero was, in fact, not accidental. He is a Russian by birth - and Russia is very special to me. My father, Leo Wiener, was born in Biatystok and immigrated to America in 1880. During all his life he was a passionate disseminator of Russian culture.

(However, I have digressed.)

So, I'm finishing my new novel, 'What Lies Under the Stone', that will be published in December of this year. It deals with corruption in the $T V$ production sector of the USA and with exploitation of talented children.

\section{LG:}

Why have you chosen this title for your novel?

\section{Wiener:}

Have you seen what happens when you turn over a big stone? You see the various things that accumulated there over the years. Something like that happens in my novel: during a legal process, the TV business shows its seamy side...

In this novel, I wanted to explore the formation of a gifted child's character. This subject is close to me. After all, I was also a kind of 'Child Prodigy'...

At the end of the conversation, Norbert Wiener said some words to the readers of the LG:

It is a great honor for me to communicate personally with my colleagues from other countries and to see a great interest and understanding of the questions of automatics. I am glad that me and my wife have come to this beautiful and friendly city.

During the lecture at the Polytechnic Museum he was asked about his coming plans in literature. His answer was:

Last year I published my first novel and I intend to write another one together with my colleague, Doctor Asimov from the University of Boston. I never think about how many books I'm going to write. I find satisfaction in writing novels when I have some free time.

Being a great mathematician and the founder of cybernetics, Norbert Wiener took his work in literature very seriously.

We know nothing about what happened to the novel 'What Lies Under the Stone' and to the Wiener's plans of co-operation with Isaac Asimov ...

Most of Wiener's writings are non-fiction books. We know that he created two autobiographies: 'Ex-Prodigy, My Childhood and Youth' and 'I Am a Mathematician. The Later Life of a Prodigy'. The two of his most popular works in cybernetics are 'The Human Use of Human Beings' [9] and 'God and Golem, Inc.' [10]. In these works, it can be clearly seen that, compared to his contemporaries, Wiener had a 
better understanding of the influence of technical progress on our society and that he believed in the power of human intellect, and human qualities.

In 1993, the MIT Press published one of his unknown works: 'Invention: The Care and Feeding of Ideas' [11]. This novel about the life of an inventor in the pitiless modern society has a remarkable dedication:

To the Massachusetts Institute of Technology, a home for the creative intellect.

One of Wiener's readers was the famous astronomer, President of the Armenian Academy of Sciences, Victor Ambartsumian.

P. Masani, who was a pupil of Norbert Wiener and his biographer, published in 1990 a remarkable biography entitled 'Norbert Wiener. 1894-1964' [12], where he presents a letter from Ambartsumian to Wiener (dated Janurary 25, 1963):

Dear Professor Wiener,

Many thanks for the copy of your novel 'The Tempter'. I have just finished reading the book and should like to say that it interested me very much. As you know we have here almost forgotten the times when there were private companies in our country. Therefore a novel describing the activities of companies as regards to application of new scientific ideas and technical inventions and the moral conflicts arising from these activities has opened to me an unknown aspect of the life of your country. Perhaps it will be useful for our young generation also to be acquainted with these problems.

Therefore I think that it is worthwhile to publish here a translation of this book and I suppose to try to do this through State Publishing House. Of course, this is only my intention and I write this to you only to show how much I was impressed by your novel.

Being an astronomer almost completely devoted to my science I have still some interest in mathematical problems and therefore I take this opportunity to send you my deep appreciation of your research work.

With kindest regards,

Yours sincerely,

\section{Ambartsumian.}

This project was never carried out, but after a while Ambartsumian received from Wiener a very cordial letter of gratitude...

Wiener's interest in literature was so great that he even tried to write a screenplay. In 1952 he sent a screenplay project to Alfred Hitchcock.

In the covering letter he wrote:

I have recently been in Mexico working in a scientific laboratory where I have run into a combination of characters and even of possible situations lending themselves ideally to a suspense and horror movie of the type in which you are expert. Together with my daughter, Miss Peggy Wiener, and an American doctor, Dr. Morris E. Chafetz, we have written a synopsis of the proposed movie. Because we are without experience in screen technique, we have not attempted to go 
further and write it up as a scenario. This synopsis has been registered with The Authors' Guild in New York, and we should be delighted to pass it on to you for examination if and when it should be possible. [14].

We don't know what happened to this screenplay ...

\section{Aleksey Lyapunov}

Aleksey Lyapunov was a descendant of an old noble family which originated numerous outstanding figures of Russian science and culture who lived and worked in the $19^{\text {th }}$ and $20^{\text {th }}$ centuries. Aleksey Lyapunov (1911-1973) began to work in the field of cybernetics in the early 50s. By that time he was already a well-established scientist, famous for his works in the field of descriptive set theory, mathematical statistics and geophysics. His erudition combined with extended scientific interests allowed him to become the leader of a new science. Aleksey Lyapunov did an enormous work trying to understand the fundamentals of cybernetics, to define the subject of this science, to classify its main directions and problems.

In the early 50s, the official ideological authorities of the USSR and many Soviet philosophers condemned cybernetics as a 'bourgeois pseudo-science'. It's quite enough just to mention the article: 'Whom Does Cybernetics Serve?' that was published in the Issue 5 of the magazine 'Voprosy Filosofii' ('Problems of Philosophy'), 1953. It was placed in the section 'Critique of Bourgeois Philosophy'. The author of this libel who hid himself behind the pseudonym 'Materialist' wrote:

"The theory of cybernetics which endeavors to apply the functioning principles of the brand-new computers to diverse natural and social phenomena... is a pure reductionism transformed into idealism. It is a barren flower on the tree of knowledge" [15].

In 1954, in the 'Short Philosophical Dictionary' ('Kratkii Filosofskii Slovar') cybernetics was defined as

"A reactionary pseudo-science that emerged in the USA after the World

War II and became widespread in capitalist countries" [16].

It is easy to imagine what it was like in the Soviet Union to disseminate the 'reactionary pseudo-science' in those hard times. But Aleksey Lyapunov practiced this dissemination on a regular and professional basis.

Lyapunov realized at once that mathematical theory of control demands a detailed analysis of different control systems, deep research of the processes of emergence, transmission, storage and processing of information in engineering, nature and economics. This could create a new approach that was named 'cybernetic' by Norbert Wiener. Encyclopedic erudition so characteristic of Lyapunov perfectly suited for integration of facts and theories from different fields of natural science with the aim of generation and development of theoretical cybernetics.

Lyapunov never limited himself to mathematics in his scientific work - he was a real encyclopedic scientist who worked diligently and effectively in different branches of science. But in spite of Lyapunov's extended scientific interests he always remained highly professional in his scientific works. Biologists believed him 
to be a biologist, geophysicists - a geophysicist, philosophers - a philosopher. His great erudition in combination with a holistic, integrated approach to natural science and to the whole complex of scientific knowledge have become a kind of fruitful ground that was just perfect for growing the ideas of cybernetics.

1n 1954-1956, Lyapunov gave lectures on cybernetics to many different audiences - he spoke to mathematicians, engineers, biologists, philosophers and linguists, explaining the essence of cybernetics and its true purpose.

Aleksey Lyapunov possessed wonderful human qualities and remarkable pedagogical abilities. He was a responsive and friendly person; he never limited himself to a concrete subject he was teaching, but always drew the audience's attention to diverse connections between the taught subject and the general system of scientific knowledge and pointed out the unexplored fields of science.

Naturally, it was impossible to organize active promotion and development of the new science without appropriate literature. So, Lyapunov concentrated on creating and publishing of the necessary materials. He achieved a success in publication of the translation into Russian of Wiener's 'Cybernetics' and other foreign publications, the publication of Igor Poletaev's 'Signal' [17] (it was the first original book on cybernetics written in our country!), made agreement with 'Fizmatgiz' to launch his collections 'Problemy Kibernetiki' ('Problems of Cybernetics'). The friends and pupils of Aleksey Lyapunov helped him to fulfill these noble and bold enlightenment projects.

At the beginning of 1954, Anatoly Kitov, who was one of Lyapunov's pupils, prepared a voluminous report on the essence of cybernetics for a seminar held at one of the research institutes. Materials of this report were developed and amplified by Academician Sergey Sobolev and Aleksey Lyapunov, whereupon the paper was published with the title 'The Main Features of Cybernetics' in the Issue 4 of 'Voprosy Filosofii', 1955 [18]. This was the first positive article on cybernetics that received the official approval of Soviet authorities.

But it was not enough for further development of cybernetic research and formation of cybernetics as an integral field of knowledge. It was necessary to create a consolidated team of scientists who would be capable of organizing and conducting cybernetic research programs. The other goals were to get familiar with the process and results of similar studies performed abroad, to formulate the problematic and find effective and unified ways of collaboration for heterogeneous teams of scientists who were ready to work in this field of science. All these goals were achieved in the seminar on cybernetics organized by Lyapunov at the State University of Moscow in 1954. This seminar had become the first coordinating center for cybernetic research in the Soviet Union. It attracted interest across a broad range of specialists (mathematicians, engineers, biologists, philosophers, physicists etc.) and talented young people. Very soon it had become a city-wide and even a nation-wide event. Almost every team formed afterwards with the aim of conducting cybernetic research was somehow connected with this Seminar. It was named a 'Big Lyapunov's' seminar on cybernetics.

This seminar existed for 10 years (1954-1964). 120 meetings (with the same number of reports and discussions) were conducted during this period of time. Surely it is enough to look at the list of these reports [19] to understand that the research area 
and the level of reports and lecturers met all requirements of the head of the Seminar and corresponded to the needs of cybernetic science in our country.

Among the goals of the Seminar were explanatory work with the aim of vast dissemination of cybernetic ideas and active struggle against negative attitude towards cybernetics, which was not uncommon in the Soviet press. Over the years, several hundreds of popular lectures and reports concerning cybernetics, its subject-matter, essence and goals were presented by the head of this Seminar Professor Lyapunov and its participants, who severely criticized the unprofessional articles on cybernetics that often appeared in the Soviet magazines and newspapers.

The Seminar of Aleksey Lyapunov became a kind of nucleus of the cybernetic research in the USSR. It had given rise to many local 'small' cybernetic seminars headed by participants of the 'Big' Seminar.

This success naturally led to the idea of establishing an Institute of Cybernetics of the USSR Academy of Sciences. Creation of an academic institute for researches in a new progressive field of science was a standard practice in every scientific community.

After the official 'rehabilitation' of cybernetics, numerous academic institutes of this kind were established in different republics of the USSR, such as the Institute of Cybernetics of the Academy of Sciences of Ukraine, the Institute of Engineering Cybernetics of the Academy of Sciences of Belarus. Other Institutes of Cybernetics were established in Georgia, Uzbekistan, Azerbaijan, Estonia etc.

A project to establish such an Institute in Moscow, at the Department of Physical and Mathematical Sciences of the USSR Academy of Sciences was seriously considered during the period of 1959-1961. In the archives numerous documents are preserved concerning this project. A lot of these materials and documents were published in 1998 in the book 'Essays on the History of Computer Science in Russia' (Ocherki Istorii Informatiki v Rossii) [20].

But why was not this Institute established by that time, when everyone was fascinated by cybernetics?

It is known that there was some disagreement among participants of the consultations concerning the main research directions of the future institute. Most of the participants were eminent scientists already possessing a big academic experience in different fields. Accordingly, they had different views of cybernetics and of the scientific problems the future institute had to deal with.

There were also conflicting opinions concerning the staff structure. Who was able to head the Institute of Cybernetics? The fact that Lyapunov decided to move to Novosibirsk in early 60s may have influenced the situation, too.

With the aim of coordinating research activities, the 'Scientific Council on the Complex Problem of Cybernetics' was established at the USSR Academy of Sciences in 1959. Academician Aksel Berg, an outstanding scientist and organizer of science, was appointed as the first chairman of the newly-formed Council. Under his chairmanship, the Council became the national center of cybernetic research. Aleksey Lyapunov, Igor Poletaev and other scientists made major contribution to creation and development of this Council.

In 1958, Lyapunov launched his famous series of collections 'Problemy Kibernetiki' (which is known abroad as 'Systems Analysis'). He remained the editor of these collections until the end of his life. Under his editorship, 29 issues were 
published. Altogether, 41 issues of 'Problemy Kibernetiki' appeared during the period of 1958-1984.

Thus, the situation changed. Due to the heroic efforts made by Lyapunov and his associates, cybernetic science took its deserved place in the Soviet Union. As a matter of fact, exactly at this point began the active development of this science in our country.

Lyapunov contributed a huge amount to formation and development of the national cybernetics. His merits are very great indeed, and the first 10-12 years of the Russian cybernetics is fairly called 'The Lyapunov Period'.

The work performed by Aleksey Lyapunov obtained international recognition. In 1996, the IEEE Computer Society honored Lyapunov (posthumously) as a 'Computer Pioneer' who 'Founded Soviet Cybernetics and Programming'.

Here are some reminiscences of Lyapunov's contemporaries:

\section{Julius Schreider:}

What enabled cybernetics to unite people who were completely different? Why did the Lyapunov's seminars become the main center consolidating people of different professions and scientific views?

What exactly happened in the early period of cybernetics? I suppose, it was the process of consolidation of scientists who were united by cybernetics as a field of scientific activity allowing to detect natural origins in the world of organizations up to the intellect itself. The idea to find a rational explanation of how the human intellect works seemed to be just fascinating... [21].

\section{Modest Haase-Rapoport:}

Aleksey Andreevich devoted his whole life to science and served his country unselfish. The scope of his scientific interest was so vast that he can truly be called a person of encyclopedic knowledge.

His attitude to cybernetics resembled the attitude of a priest to his religion. It was sacred to him. Understanding living organisms by means of natural sciences is a goal of utmost significance... It was definitely very important to him [22].

In November 1971, Vladimir Uspensky wrote in his birthday greeting to Aleksey Andreevich:

Over many years I admiringly observed you working. I consider you to be one of the heroic figures of Russian science. For the younger generation, it's hard to believe how much fearlessness, persistence and commitment to principles one needs to give birth to a new science, cybernetics [23].

At the beginning of 1962, Aleksey Lyapunov moved to Novosibirsk upon invitation of the administration of the Siberian Division of the USSR Academy of Sciences and remained there for the rest of his life. While living in Novosibirsk 'Akademgorodok' (the Novosibirsk Academic Village), he worked in the field of theoretical and applied cybernetics with all his inherent energy and great brilliance. It would hardly be an exaggeration to say that when Lyapunov moved to Novosibirsk, the main center of Soviet cybernetic research moved here along with him. 
There, he took part in forming of scientific teams. He played an important role in creating of the Division of Cybernetics at the Institute of Mathematics. He organized the Department of Mathematical Analysis and the Department of Theoretical Cybernetics in Novosibirsk State University.

Lyapunov was an outstanding teacher and a remarkable disseminator of scientific knowledge. He was engaged in the teaching process at all stages of education, from the university down to the primary school level. He never limited himself to teaching mathematics. His interests extended to the whole range of natural sciences. He also occupied himself with the problems of education and upbringing.

Lyapunov's pedagogic activity reached its highest point at the Novosibirsk Academic Village. He took part in the organization of Siberian Mathematical Olympiads. Together with Academician Lavrentiev, he initiated the establishment of the famous Physico-Mathematical School (PMS) at the Novosibirsk University. It was the first school of this type in our country. Lyapunov had a great influence on the process of formation and development of this new type of school.

Lyapunov's work in the PMS left a general imprint on school education. It was not just a well-organized process of teaching mathematics. It was also living example of selfless devotion to science and society.

Lyapunov was a remarkably charismatic person, loved by successive waves of pupils and students. His sociability and friendliness, his breadth of interest and generosity of scientific communication were valued by people working in different siences. In the $60 \mathrm{~s}$ and in the early $70 \mathrm{~s}$ he was regularly visited by mathematicians and physicists, biologists and linguists who came from Moscow and from other cities of the country. The Academic Village hosted many national and international conferences on cybernetics and programming.

In 1973, Igor Poletaev wrote:

The scientific truth was his sacrificial altar, and the search for the truth was his religion. His attitude to cybernetics resembled the attitude of a priest to his religion. His self-denying and knightly serving the truth was supplemented with his fascinating personality and his ability to be precise and understandable at the same time. ... Even disputable opinions sounded attractive and almost convincing, when he was talking. Every conversation with him was an intellectual event and an aesthetic experience [24].

Today's reader will surely feel that Aleksey Andreevich Lyapunov was not only an outstanding mathematician. He will remain in history as a remarkable humanist possessing precious human qualities.

\section{$4 \quad$ Leonid Kantorovich}

The name of Academician Leonid Kantorovich (1912-1986), his life, work and struggle for his principles hold a special place in the history of the $20^{\text {th }}$ century.

The early manifestation of his talent, mathematical discoveries and formulation (at the age of 27!) of the scientific methods of control over economics and planning, an 
extraordinary breadth of interests, uncompromising of a fighter on one hand, modesty and nobleness on the other. All this forms the unique phenomenon of Kantorovich.

The mathematical discoveries of Kantorovich have become the basis of major new directions in mathematics. He is fairly considered to be one of the most striking mathematicians of the last century. Already in the 1930s, he made a big contribution to theoretical mathematics. Functional analysis holds a special place in the mathematic works of Kantorovich. With his classical works, Kantorovich turned functional analysis into the natural language of computational mathematics.

At the same time, he believed economical cybernetics to be the work of all his life. The linear programming discovered by Kantorovich constitutes the nucleus of economical cybernetics. This is a new and very significant conception. It allows turning economics into an objective science which leads to the most effective results of economic activity.

One of the closest associates of Kantorovich, Academician Valery Makarov, wrote:

He achieved high-class results in functional analysis, function theory, computational mathematics. He has written a number of major works on set theory, theory of computer programming etc. He has written (alone and in joint authorship) about ten considerable monographs on mathematics. One would think it is quite clear that Leonid Kantorovich is a mathematician to the core... As a matter of fact, it is not the whole truth. His phenomenon is characterized by the fact that at the same time he is an outstanding economist who has fundamentally changed the economic thinking and the understanding of economic events; he has become the founder of a new economic school [25].

Another pupil and adherent of Kantorovich, Professor Simon Kutateladze observed:

In the $20^{\text {th }}$ century, two eminent mathematicians, John von Neumann and Leonid Kantorovich, devoted themselves to the economic subject matter. The first one developed game theory as an instrument of study of economic behavior, the second one elaborated linear programming as an instrument of taking optimal decisions about optimal use of limited resources. The significance of the studies performed by von Neumann and Kantorovich goes far beyond the borders of their outstanding technical results. Their achievements have clearly shown that the modern mathematics possesses large-scale possibilities to apply economic analysis to practical problems. The distance between economics and mathematics became shorter. Economics remains humanity, but it becomes mathematized...[26].

Academician Israel Gelfand said:

Why do I consider Leonid Kantoorovich to be a genius? It is very simple - he combines in himself two cultures: the first one pertaining to humanities and the second one pertaining to mathematics... In the $20^{\text {th }}$ century, very few people were capable of such a synthesis... What we see is an integral inner spirituality that equally affects all areas of his work [27]. 
Leonid Kantorovich was a child prodigy. He was good at counting already at the age of two. As a child he received a special scholarship that was established for talented children.

In 1926, at the age of 14, Leonid Kantorovich was admitted to the Physicmathematical Faculty of the University of St. Petersburg. There were not many students at the faculty, but among the classmates of Leonid Kantorovich were some with great talent: the future Academicians S. Sobolev and S. Khristianovich, corresponding member D. Fadeev, Professor S. Mikhlin. The latter wrote in his memoirs about the young Kantorovich:

The first impression I got of him was that he is a shortish boy... a childish boy with rosy cheeks. What was he doing here, I wondered, such a little boy at the University? I was almost 19 and considered myself to be an adult man, and he wasn't even 15 yet... He was exceptionally talented, you could feel it at once. I remember how astonished we were when his first works had been published, less than a year after he was admitted to the University. My classmates and I were really shocked. We were in the third year at the University, and he was in the second, but the idea of publishing student's works seemed to us unrealizable [28].

His first research, Leonid conducted under the direction of Gregory Fikhtenholts, who was a prominent mathematician and a Professor at the University of St. Petersburg (Leningrad). Already as a student Kantorovich became famous for his works on the descriptive theory of functions. At the age of 18 , he successfully graduated from the University. Professor Fikhtenholts wrote about his young graduate:

During a period of 4 years we were in regular communication with each other, so I can certainly state that this young man (now at the age of 18) possesses an extraordinary mathematical talent [29].

After graduating from the University, Leonid Kantorovich pursued postgraduate studies. He also began his teaching career at the University and at the newly opened Leningrad Institute of Engineers of Industrial Construction, where he became a Professor two years later. The Department of Mechanical Engineering at this Institute was of a very high level. The problems of designing large objects like turbines, airplanes and complex constructions raised his interest. He invented a range of new computational approaches, and in 1936 he published his work (written in joint authorship with V. Krylov) 'Methods for the Approximate Solution of Partial Differential Equations'. This monograph was the starting point of computational mathematics as an autonomous science.

Leonid Kantorovich is the author of more than 300 scientific studies which are characterized by a strikingly large scope of research directions. They are united not only by his personality, but also by the integrity of his work and the interpenetration of methods and ideas used in the process of resolving the most different problems.

The same inner integrity of Kantorovich determined his life and civic engagement. He was honest and daring both in science and in life. "It is the scientist's duty and right to tell the truth" said Kantorovich in his last interview. It is not just a declaration, but a moral attitude confirmed by his whole life and his actions as a scientist and a citizen. As a scientist, Kantorovich did not differentiate among 
fundamental problems or applied problems; problems related to mathematics or to humanities; problems or not prestigious. He devoted himself to any challenging problem with equal interest and endeavor and proved by his works that a real scientist could uncover the true depth of a minor problem that would bring it to the highest level of significance. As a citizen, he defended the truth irrespective of the predominant opinions and fearlessly struggled for his ideas for humanity's sake.

The efficiency of Kantorovich's approach showed up most clearly in the case of the 'plywood trust'.

In 1938, Kantorovich received a request from the employees of a Central Laboratory of the Leningrad plywood trust. They asked him to recommend a numerical method of calculating a rational plan of machine utilization. It was necessary to organize a complex of five technological processes involving five peelers of eight types. The machines had different productivity, so it seemed to be impossible to calculate the outcome which presumably depended only on casual circumstances.

To solve this problem, some totally new ideas were needed. The central part of the Kantorovich's invention is constituted by optimality criteria. The new method allowed proposing different schemes of examination of options.

A little booklet with the title 'Mathematical Methods in the Organization and Planning of Production' appeared in 1939. In this study he developed mathematical formulation of the industrial optimization problems, effective techniques of problem solving and methods of economic analysis of these problems. Thus, Leonid Kantorovich formulated the mathematical technique known as linear programming, which had a great influence on the development of economic science.

On the basis of this study, Kantorovich created a whole number of further works. Years after, in 1975, these works have brought him a Nobel Prize in Economics.

Unfortunately, the invention of Kantorovich did not receive recognition in the USSR. Application of mathematical methods to economics (which belongs to humanities) was received with hostility by the traditional economists and official philosophers: they considered it a breach of the purity of Marxist theory that condemned mathematical economics (together with genetics and cybernetics) as a 'bourgeois pseudo-science'.

During the war period, Kantorovich engaged more and more in economics. He created the first version of a big book titled 'The Best Use of Economic Resources', where he formulated the design principles for the systems of economic indicators stimulating fulfillment of the set tasks. This book was not published until 1959. For over 20 years he had been waiting for publication of his papers in the field of economics that made him world-famous!

Overcoming the Iron Curtain and other limitations, Western scientists gradually learn more about the discoveries made by Kantorovich. Having studied his first publications, they unconditionally acknowledged his priority. They've even made great efforts to translate his pioneer work into English and to get it published.

The first-rate American authority in the field of linear programming G. Dantzig wrote that Kantorovich's paper dated 1939 contains nearly all applications that have become known in 1969. Subsequently, a similar technique has been created independently of Kantorovich by the American economist Tjalling Koopmans and other scientists. 
In 1975, the Nobel Committee decided to award the Nobel Prize in Economics jointly to Leonid Kantorovich and Tjalling Koopmans "for their contributions to the theory of optimal use of resources". The outstanding achievements of the scientists from the two countries have been recognized and appreciated.

There exists an opinion that the scientific life of Leonid Kantorovich was quite trouble-free. Indeed, he was a child prodigy, admitted to the University at the age of 14. At the moment of graduation, he already was a prominent mathematician and the author of about 10 papers; he became a Professor at the age of 20, a Doctor of Sciences at the age of 23 (he was given this degree without thesis defense). At 26 years he was the head of a scientific school, the winner of National Contest for Young Scientists.

But if you look closer at the facts of his biography, you will see that it was not so rosy.

Archive materials shed new light upon the events related to his struggle for recognition and application of the scientific techniques of the organization and control of economic activity.

Leonid Kantorovich constantly received invitations to different international conferences on computational mathematics, operations research, mathematical economics etc. Being a member of Program Committees of different international congresses, and an honorary member of several international scientific societies, he had no possibility to attend these events because he was not permitted to travel abroad. It was called in the Soviet Union 'nevyezdnoi' ('non-exit')!

In his Biography Card filled out by Kantorovich in February, 1986 are specified the Universities having awarded him an honorary doctorate (Honoris Causa):

The University of Glasgow (1966, Great Britain)

The University of Grenoble (1967, France)

The Warsaw School of Economics) (1967, Poland)

The University of Nice (1968, France)

The University of Munich (1970, FRG)

The University of Helsinki (1971, Finland)

Yale University (1971, USA)

The University of Paris 1 Pantheon-Sorbonne (1975, France)

The University of Cambridge (1976, Great Britain)

The University of Pennsylvania (1976, USA)

Indian Statistical Institute (ISI), Calcutta (1977, India)

The University of Economics, Prague (1981, Czechoslovakia)

Martin Luther University, Halle-Wittenberg (1984, GDR)

In the private archives of Kantorovich there are many documents concerning his visits abroad.

After Khrushchev's so-called 'thaw', he was sometimes allowed to go beyond the 'Iron Curtain'. In June of 1966 he received permission to go to Great Britain, to attend his award ceremony - The University of Glasgow had awarded him the degree of Doctor of Laws. In 1967, he was sent to France where he was awarded the degree of Doctor of Laws by the University of Grenoble. 
Thereupon the Academician Kantorovich had no possibility to participate even in the most significant scientific forums that took place abroad. He was prevented by the authorities from travelling to other countries to accept the awards that not only the scientist but the Soviet Union itself could be proud of!

Thus, Leonid Kantorovich was named in absentia as the recipient of the honorary degrees in Nice (1968), Munich (1970), Helsinki (1971) and even in Paris (Sorbonne, 1975). The award ceremony at Yale University did not take place - according to the University Charter, the degree couldn't be awarded in absentia.

In those days, the receipt and transfer of correspondence for the Soviet scientists was carried out through the Foreign Department of the Presidium of the Academy of Sciences. When a letter of invitation came - even the most honorary one - it was sufficient just to store the letter in some office of the Presidium and give it to the addressee after the expiry of the set term. It was also possible to conceal the receipt of such letter.

So, in 1971 the Foreign Department simply did not inform Leonid Kantorovich that he was awarded an honorary doctorate by the University of Helsinki. Actually, Kantorovich recognized it by chance, when he received (to his home address) a letter from a Finnish tailor (!) asking him about his clothing sizes, in order to make a ceremonial mantle and a hat for the award ceremony.

In 1976, after a long period of writing letters and procrastination, Kantorovich was at least allowed to go to Cambridge personally to receive an honorary doctorate.

Here, I would like to add something else concerning this high award.

Later, on July 6, 1983, there was a short item in the newspaper titled 'Vechernaya Moskva' ('Evening Moscow'), placed in the section 'Information Desk', which said:

Question: What scientists from Russia and the Soviet Union were awarded honorary membership of the Cambridge University?

Answer: The honorary doctorate of the Cambridge University (Great Britain) was awarded to K.A. Timiryazev in 1909. Along with Timiryazev, this high degree was awarded to the biologist I.I. Mechnikov (1891), the chemist D.I. Mendeleev (1894), the physiologist I.P. Pavlov (1912), the biochemist V.A. Engelgardt (1970), the mathematician and economist L.V. Kantorovich (1976).

The physicists P.L. Kapitsa (1925), L.D. Landau and I.M. Lifshitz (1962) were awarded honorary membership of Trinity College, Cambridge.

This information was provided by the Institute of History of Natural Science and Technology of the Academy of Sciences of the USSR [30].

It seems to me that the above short item, which maybe remained unnoticed by the historians of science, is a real condemnation to the Soviet Academy of Sciences and to the whole Soviet system that has, for many decades (!), kept the great scientists like Leonid Kantorovich on the black list of persons who were not permitted to travel abroad...

In 1957, a government decision was made to establish a big new scientific center in the eastern part of the Soviet Union, the Siberian Branch of the USSR Academy of Sciences. Leonid Kantorovich was one of the first scientists who were invited to work in the Siberian Branch. In 1960, a team of Leningrad mathematicians headed by 
Kantorovich moved to Novosibirsk and joined the Institute of Mathematics of the Siberian Branch as the Department of Mathematical Economics.

During the period of 1960-1970 Kantorovich was the deputy director of the Novosibirsk Institute of Mathematics and the Dean of the Department of Computational Mathematics of Novosibirsk State University. Since the founding of the 'Siberian Mathematical Journal' and until the last days of his life, Kantorovich remained a member of the Editorial Board determining the scientific image of the Journal in applied functional analysis and mathematical economics. In 1958, he was appointed a Corresponding member of the Department of Economics of USSR Academy of Science, and in 1964 - a Member of the Department of Mathematics.

The Department of Mathematical Economics created by Kantorovich in Siberia was the first one to use a complex approach to the problems of application of mathematical methods in economics.

During this period, Kantorovich was engaged in the scientific organizational work. The conduction of many several national and international conferences and meetings on the problems of application of mathematical methods in economics was entirely due to his initiative. He organized the training of specialists in the area of economical cybernetics.

In 1971, Leonid Kantorovich moved to Moscow where he was appointed the head of the Department of System Modelling of scientific and technological advancements at the Scientific Research Institute for System Studies of the USSR Academy of Sciences.

Research work on computer architecture and programming hold a special place in the intellectual legacy of Kantorovich. He was one of the first scientists to understand the great significance of computers and informatics. During the period of 1953-1956, Leonid Kantorovich was engaged in the popularization of computer science.

In his articles Kantorovich wrote:

In the history of cultural and technological development of human society a special place is held by the discoveries and inventions having affected not just one but nearly all the fields of the human activity. Among these discoveries and inventions of major importance we can name book-printing, discovery of the New World, steam engine, weaver's loom, railway, electricity, bacteriology, radio, aeronautics, television and, finally, atomic energy [31].

General ideas of Leonid Kantorovich concerning the complex development of machine mathematics (methods, algorithms, programming, computer architecture) also deserve consideration.

The scientific school of Professor Kantorovich, be it in the area of mathematics or economics, is not just tens of his immediate pupils. There are lots of his followers whose scientific thinking and activities were greatly affected by the works of Kantorovich and by personal communication with this outstanding scientist.

Leonid Vitaliyevich set for his pupils and followers a brilliant example of honesty, uncompromising and firmness in science, of objectivity and friendliness. Throughout his life, Kantorovich attracted and drew about him people by force of his fascinating personality and wealth of ideas, remarkable kindness, modesty and sociability, his human quality. It was a pleasure for him to work with the younger generation, and he was always surrounded by young people. 
Many authors try to compare the life and work of the two outstanding mathematicians of the $20^{\text {th }}$ century - Leonid Kantorovich and John von Neumann. There is really some similarity between the figure of Kantorovich who was characterized by extended scientific interests and made a great change not only in mathematics and mathematical economics, but also in computer science, and the figure of von Neumann.

\section{$5 \quad$ Andrey Ershov}

We have already mentioned the fact that, in the beginning of the 1960s, when many of the leading Soviet mathematicians moved to Siberia, the Novosibirsk Academic Village became, in essence, the national center of cybernetic science.

Andrey Petrovich Ershov (1931-1988) graduated from the State University of Moscow in 1954. This was the first group of graduates in the specialty 'Programming'. Then, Ershov pursued postgraduate study under the direction of Aleksey Lyapunov.

Subsequently, Ershov wrote:

From the very first lectures Aleksey Andreevich completely captured the minds of the students. He was an ideal guide of new ideas. The magnetic influence of his bright appearance and an exceptional eloquence, his selfless enthusiasm and merry passion, his complete availability to the students without any familiarity - all this at once made him the most popular lecturer... [32].

Already in the late 50s, due to his brilliant studies Ershov became one of the leading Soviet programmers. After the establishment of the Siberian Branch, Ershov received an invitation from the Director of the Novosibirsk Institute of Mathematics, Academician Sergey Sobolev. He was proposed to organize and head the Department of Programming of this Institute. In 1960, Ershov moved to Novosibirsk.

Many authors have written about Andrey Ershov. It suffices to name the interesting voluminous book [33] containing reminiscences and photographs, that appeared in Novosibirsk in 2006. In this book and in many other publications you can find detailed information about Ershov's life, his personal achievements and the achievements of his team, concerning theoretical and applied works in informatics. Surely, programming holds one of the central places in Computer Science. And it happened so, that at the beginning of this new branch of science stood such a talented, energetic and honest person as Andrey Ershov.

One of the closest friends and associates of Ershov, Svyatoslav Lavrov, said about him:

Andrey Petrovich was the leader of the native programming. Any of his undertakings, even if it didn't seem significant at the beginning, would draw the attention of many other programmers and set them in motion. A wide range of his popular science lectures found a broad response among programmers from the whole world [34].

Indeed, Andrey Ershov made a considerable contribution to the organization of international cooperation. This side of his activity had a great and productive 
influence on the development of programming science in general and the recognition of the achievements made by the Soviet scientists.

It appears that Andrey Ershov, as opposed to Leonid Kantorovich, was allowed to travel abroad. Below, we will site a few opinions of Ershov's contemporaries about his international contacts:

\section{Boris Trakhtenbrot:}

Andrey Petrovich maintained friendly relations with most of the outstanding programmer scientists and collaborated with the leading scientific centers from the whole world. It happened by the time when a trip abroad, especially to the 'capitalist countries', was a rare privilege in the Soviet Union. Fortunately, Andrey Petrovich felt very obliged to have this privilege and did anything possible to relieve the isolation of those who were... restricted in their contacts with their foreign colleagues [35].

\section{Andrey Bers:}

Andrey Petrovich thoroughly organized and maintained the relations with numerous foreign and native colleagues and groups of scientists. He received an immense quantity of letters from the whole world and punctually registered all materials, incoming and outgoing letters. On the base of these papers he created a unique data library containing reports, preprints and publications.

Many foreign colleagues came to the Academic Village to visit Andrey Petrovich, and we had the possibility not just to see and hear them, but (again, due to Andrey Petrovich's efforts) also to discuss our results and to talk, along with Ershov, to the most eminent programmer scientists of the world: John McCarthy, Donald Knuth, Edsger Dijkstra, Tony Hoare, Aad van Wijngaarden and many others [36].

\section{Heinz Zemanek:}

Andrey Ershov was a prominent and highly distinguished person in the international community of specialists in the area of information processing...

My American colleagues often spoke of Andrey with respect ...

After the establishment of IFIP in 1962, Andrey was appointed a representative of the USSR Academy of Science in the Technical Committee 2 (TC 2).

He endeavored to organize the participation of the USSR in IFIP, and used every possibility to present the works of his pupils and colleagues and to enable them to take part in the events conducted by IFIP. We all know that it was a hard task [37].

In 1974 Ershov was made a Distinguished Fellow of the British Computer Society. This grade is awarded for 'Outstanding Contributions to the Advancement of Computing'. Earlier than Ershov, only five specialists (among them, two English scientists) were awarded this honorable grade: Maurice Wilkes, Edsger Dijkstra, Grace Hopper, Christopher Strachey and James Wilkinson. 
In my opinion, the major achievement of Andrey Ershov's activity in international scientific co-operation was the Symposium 'Algorithms in Modern Mathematics and its Applications' which was dedicated to Al-Khorezmi, the outstanding ninth-century mathematician who gave his name to the word 'algorithm'. This event took place in September of 1979, in the city of Urgench, Uzbekistan. Andrey Ershov and Donald Knuth acted as co-chairmen of the Symposium.

In the private Ershov's archives hundreds of letters are preserved concerning the preparation and conduct of this Symposium. Let us cite some extracts from these papers:

In his letter to Donald Knuth of April $7^{\text {th }}, 1977$, Ershov is planning:

Concerning the scientific pilgrimage to the place of birth and youth of Al-Khorezmi.

I propose you to consider the following idea. The conducting of the colloquium with the title 'Algorithm in Modern Mathematics' in Khorezm or somewhere else in the region, beginning from Tashkent. Scientific organizers: D. Knuth and A. Ershov. Promoter: the Uzbek SSR Academy of Sciences. Number of participants: 10 persons from foreign countries and 10 persons from the USSR. Timeframe: May of 1978. Naturally, any counter-offers are welcome [38].

At first, Donald Knuth and Andrey Ershov prepared and coordinated the number and the membership of participants. It included the most eminent scientists from the Soviet Union and other countries who were engaged in computational science.

So, Ershov sent invitation letters to the participants and received letters of response. Mostly, the invitees expressed their gratitude and informed Ershov about their intention to come to Urgench.

At the same time, Ershov realized engaged in correspondence with the academic authorities: he had to obtain entry permits for the foreign guests.

Moreover, he managed to obtain for some of them the status of 'a guest of the Academy of Sciences', which facilitates their financial problems.

The Urgench Symposium was the first scientific attempt to gather all material on the subject of Al-Khorezmi and his works. The Austrian scientist Heinz Zemanek played a special role in the process of preparation and conducting of the Symposium. Zemanek was quite interested in the history of science, and in particular, in the mathematics of the ancient Middle East.

The Urgench Symposium took place on September 16-22, 1979. It gathered 39 participants, among them 26 scientists from the USSR and 13 from other countries. The first speaker at the first morning meeting (September 17) was H. Zemanek. He delivered a great and remarkable report entitled 'Al-Khorezmi: his Background, his Personality, his Work and his Influence'.

After returning to Wienna, Zemanek wrote:

From the international point of view, the Urgench Symposium 1979 has become one of the most impressive scientific events. In collaboration with Donald Knuth, Andrey Ershov, acting in the name of the USSR Academy of Sciences, organized the Symposium 'Algorithms in Modern Mathematics and its Applications' that gathered many outstanding participants, such as S. Kleene, F. Bauer, G. Kaufmann and A. van 
Wijngaarden. It was a crucial experience for the development of the theory of algorithms [39].

Donald Knuth said:

... It was an unforgettable event. Instead of an 'ordinary' conference where the participants just read out their ready reports, we conducted a whole number of discussions on fundamental problems of mathematics and computational science. The desert landscape surrounding the Khorezm Oasis and the breath of history distracted us from the flood of thoughts going through our minds in the circumstances of our daily lives. It helped us to concentrate on profound ideas and philosophical thoughts turning to the future....

This Symposium - a scientific pilgrimage to Khorezm, to the birthplace of the notion 'algorithm' - has become a dream-come-true for me. Although both of us were on the list of co-chairman, Andrey carried out about $99 \%$ of the work. So I had the possibility to relax and just enjoy what was going on around me, learning many important things from the people I met there. It really was a once-in-a-lifetime experience, and I hope that many other specialists working in computational science will be able to participate in events like this one, provided that Andrey's example inspires someone else.

During this week I got to know him much better, and was especially surprised at how brilliantly he performed his manifold duties: Head of the Conference, organizer, philosopher, public speaker, interpreter and editor [40].

In the early 1980s, one of the participants of the Symposium, the English scientist M. Paterson, who was the President of the European Computer Society, published in the Bulletin of this Society a report on his journey to Urgench. In particular, he said:

This informal Symposium offered its participants exceptional opportunities to establish new academic and social contacts and to renew the old ones. It is particularly important when we need to overcome the linguistic, political and geographical gaps which so often hinder the development of our science.

I hope we shall all retain the spirit of community and collaboration which enveloped us during this delightful and unforgettable week. [41].

\section{Conclusion}

We have described in brief outline the biography of Norbert Wiener, the scientist who introduced in our scientific and everyday use the proud word Cybernetics. Special attention was given to Wiener's visit to Moscow in the Summer of 1960, at the very beginning of the 'cybernetic era'.

We have traced the main events of the lives and activities of prominent Russian scientists Aleksey Lyapunov, Leonid Kantorovich, and Andrey Ershov. They lived and worked in the middle of the last century in Novosibirsk Scientific Center. 
Evidently, they possessed, as well as a number of their disciples, remarkable human qualities.

Unfortunately, we live in difficult times. Financing of science and education is gradually reduced. The mass media are used for systematic declining of the mental and moral level of the public. The honest people attempt to resist these unfavorable trends. In our opinion, the main weapon on this difficult road is education.

Contemporary young people typically are not familiar with the remarkable scientists of the past. We hope that the presented materials in this article's narratives will help the young readers to choose a worthy way of their life.

\section{References}

1. Peccei, A.: The Human Quality. Pergamon Press, Oxford (1977)

2. Wiener, N.: Ex-Prodigy, My Childhood and Youth. Simon \& Schuster, New York (1953)

3. Wiener, N.: I Am a Mathematician. The Later Life of a Prodigy. Doubleday, Garden CityNew York (1956)

4. Wiener, N.: Cybernetics or Control and Communication in the Animal and the Machine, 2nd edn. MIT Press and John Wiley, New York-London (1961)

5. Cybernetics. The Expectations and the Results. Politechnic Readings (2), p. 64. Znanie (Knowledge), Moscow (2002) (in Russian)

6. Wiener, N.: Cybernetics or Control and Communication in the Animal and the Machine, 2nd edn. Sovietskoe Radio (Soviet Radio), Moscow (1968) (in Russian)

7. Cybernetics and the Literature. Literaturnaya Gazeta (Literary Newspaper), Moscow (June 30, 1960) (in Russian)

8. Wiener, N.: The Tempter. Random House, New York (1959)

9. Wiener, N.: The Human Use of Human Beings. Mifflin, Boston (1950)

10. Wiener, N.: God, Golem, Inc., a Comment on Certain Points Where Cybernetics Impinges the Religion. MIT Press, Cambridge (1964)

11. Wiener, N.: Invention: The Care and Feeding of Ideas. MIT Press, Cambridge (1993)

12. Masani, P.R.: Norbert Wiener. 1894-1964. Vita Mathematica, vol. 5. Birkhauser, Basel (1990)

13. Masani, P.R.: Norbert Wiener. 1894-1964. Vita Mathematica, vol. 5, p. 337. Birkhauser, Basel (1990)

14. Masani, P.R.: Norbert Wiener. 1894-1964. Vita Mathematica, vol. 5, p. 339. Birkhauser, Basel (1990)

15. Voprosy Filosofii (Problems of Philosophy), vol. (5), pp. 210-219 (1953) (in Russian)

16. Kratkiy Filosofskiy Slovar (The Brief Philosophical Dictionary). Gospolitizdat (State Polit. Publ.), Moscow. 4 edn., pp. 236-237 (1954) (in Russian)

17. Poletaev, I.A.: The Signal. Sovietskoe Radio (Soviet Radio), Moscow (1958) (in Russian)

18. Sobolev, S.L., Kitov, A.I., Lyapunov, A.A.: The Fundamental Features of Cybernetics. In: Voprosy Filosofii (Problems of Philosophy), vol. (4), pp. 136-148 (1955) (in Russian)

19. Haase-Rapoport, M.G.: The Emergence of Cybernetics in the USSR. In: Essays on the History of Informatics in Russia, pp. 245-249. Publishing Center of SB RAS, Novosibirsk (1998) (in Russian)

20. Essays on the History of Informatics in Russia. Publishing Center of SB RAS, Novosibirsk (1998) (in Russian) 
21. Shreider, J.A.: A.A. Lyapunov as the Leader of Scientific Movement. In: Essays on the History of Informatics in Russia, p. 198. Publishing Center of SB RAS, Novosibirsk (1998) (in Russian)

22. Fet, Y.I.: Stories About Cybernetics, p. 39. Publishing Center of SB RAS, Novosibirsk (2007) (in Russian)

23. Lyapunova, N.A., Fet, Y.I. (eds.): Aleksey Andreevich Lyapunov, p. 497. ‘GEO’ Affiliate of the SB RAS Publ. House, Novosibirsk (2001) (in Russian)

24. Fet, Y.I.: Stories About Cybernetics, p. 40. Publishing Center of SB RAS, Novosibirsk (2007) (in Russian)

25. Fet, Y.I.: Stories About Cybernetics, pp. 94-95. Publishing Center of SB RAS, Novosibirsk (2007) (in Russian)

26. Kutateladze, S.S.: Kantorovich, and the Mathematization of Science. In: Science and Its People, p. 59. Russian Academy of Sciences, Vladikavkas (2010) (in Russian)

27. Gelfand, I.M.: Leonid Kantorovich and the Synthesis of Two Cultures. In: Leonid Vital'evich Kantorovich: A Man and a Scientist, vol. 1, pp. 161-162. 'GEO'Affiliate of the SB RAS Publ. House, Novosibirsk (2002) (in Russian)

28. Mikhlin, S.G.: Reminiscences. In: Leonid Vital'evich Kantorovich: A Man and a Scientist, vol. 1, p. 192. 'GEO' Affiliate of the SB RAS Publ. House, Novosibirsk (2002) (in Russian)

29. Fikhtengolts, G.M.: A Review of the Articles by L.V. Kantorovich. In: Leonid Vital'evich Kantorovich: A Man and a Scientist, vol. 1, p. 259. 'GEO' Affiliate of the SB RAS Publ. House, Novosibirsk (2002) (in Russian)

30. Information Desk: Vechernaya Moskva (Evening Moscow). Moscow (July 6, 1983) (in Russian)

31. Kantorovich, L.V.: Significance of Modern Computers in Human Culture. In: Leonid Vital'evich Kantorovich: A Man and a Scientist, vol. 2, p. 21. 'GEO' Affiliate of the SB RAS Publ. House, Novosibirsk (2004) (in Russian)

32. Ershov, A.P.: Aleksey Andreevich Lyapunov. In: Lyapunova, N.A., Fet, Y.I. (eds.) Memory of Aleksey Andreevich Lyapunov, p. 82. 'GEO' Affiliate of the SB RAS Publ. House, Novosibirsk (2001) (in Russian)

33. Andrey Petrovich Ershov - The Scientist, and the Man, 504 p. SB RAS Publ. House, Novosibirsk (2006) (in Russian)

34. Programmirovanie (Programming). Nauka (Science), Moscow, vol. 1, p. 117 (1990) (in Russian)

35. Trakhtenbrot, B.A.: Memories of Academician Ershov. In: Andrey Petrovich Ershov - The Scientist, and the Man, p. 349. SB RAS Publ. House, Novosibirsk (2006) (in Russian)

36. Programmirovanie (Programming). Nauka (Science), Moscow, vol. 1, p. 105 (1990) (in Russian)

37. Programmirovanie (Programming). Nauka (Science), Moscow, vol. 1, pp. 110-111 (1990) (in Russian)

38. Fet, Y.I.: Stories About Cybernetics, p. 118. Publishing Center of SB RAS, Novosibirsk (2007) (in Russian)

39. Programmirovanie (Programming). Nauka (Science), Moscow, vol. 1, p. 110 (1990) (in Russian)

40. Fet, Y.I.: Stories About Cybernetics, p. 127. Publishing Center of SB RAS, Novosibirsk (2007) (in Russian)

41. Paterson, M.S.: International Meeting of Scientists at Khoresm. In: International Forum of Information and Documentation, vol. 5(1), p. 37. VINITI, Moscow (1980) 